\title{
Transplantation of $|\mathrm{s}| 1^{+}$cardiac progenitor cells in small intestinal submucosa improves infarcted heart function
}

Lingjun Wang ${ }^{1,2}$, Elizabeth M. Meier ${ }^{3}$, Shuo Tian², lenglam Lei ${ }^{2,4}$, Liu Liư ${ }^{2}$, Shaoxiang Xian', Mai T. Lam, and Zhong Wang ${ }^{2^{*}}$

\begin{abstract}
Background: Application of cardiac stem cells combined with biomaterial scaffold is a promising therapeutic strategy for heart repair after myocardial infarction. However, the optimal cell types and biomaterials remain elusive.

Methods: In this study, we seeded Is $\mid 1^{+}$embryonic cardiac progenitor cells (CPCS) into decellularized porcine small intestinal submucosa extracellular matrix (SIS-ECM) to assess the therapeutic potential of $|\mathrm{s}| 1^{+} \mathrm{CPCS}$ and the biocompatibility of SIS-ECM with these cells.

Results: We observed that SIS-ECM supported the viability and attachment of $|\mathrm{s}| 1^{+} \mathrm{CPCs}$. Importantly, Is $\mid 1^{+} \mathrm{CPCS}$ differentiated into cardiomyocytes and endothelial cells 7 days after seeding into SIS-ECM. In addition, SIS-ECM with CPC-derived cardiomyocytes showed spontaneous contraction and responded to $\beta$-adrenergic stimulation. Next, patches of SIS-ECM seeded with CPCS for 7 days were transplanted onto the outer surface of infarcted myocardium in mice. Four weeks after transplantation, the patches were tightly attached to the surface of the host myocardium and remained viable. Transplantation of patches improved cardiac function, decreased the left ventricular myocardial scarring area, and reduced fibrosis and heart failure.
\end{abstract}

Conclusions: Transplantation of ISI $1{ }^{+}$CPCS seeded in SIS-ECM represents an effective approach for cell-based heart therapy.

Keywords: Cardiac progenitor cell, Small intestinal submucosa, Heart regeneration, Myocardial infarction

\section{Background}

Myocardial infarction (MI) is among the leading causes of death globally. In the United States, the overall prevalence of MI is $3.0 \%$ among adults older than age 20 years, and MI caused over 1.1 million deaths in 2014 [1]. Although many patients survive acute MI, most of them subsequently develop heart failure, which likely results from left ventricular (LV) remodeling. Previous studies have confirmed that ischemic cardiomyocyte death, myocardial fibrosis, and inflammation are characteristic pathological features of cardiac remodeling after MI [2, 3]. Cardiomyocyte loss after MI has long been considered

\footnotetext{
* Correspondence: zhongw@med.umich.edu

${ }^{2}$ Department of Cardiac Surgery, Cardiovascular Center, The University of

Michigan, Ann Arbor, Ml 48109, USA

Full list of author information is available at the end of the article
}

irreversible, with the heart lacking sufficient regenerative capacity [4-6].

Heart transplantation is the only curative treatment for heart failure, but is subject to significant limitations, such as lack of available donors and problems with immune rejection or infection [7]. Stem cell-based therapies have been proposed as a potential strategy to promote regeneration of the injured myocardium. Previous studies had shown that cells were lost rapidly after direct injection into the myocardium, intracoronary injection, or intravenous injection [8-13]. A promising alternative strategy has been to use biomaterials to provide an adequate threedimensional scaffold for transplanted cells, thereby increasing cell viability and even producing better cardiac tissue models in vivo $[14,15]$. Various types of cells have been combined with different materials for cardiac repair and generation of new myocardium, including induced 
pluripotent stem cells, cardiomyocytes $(\mathrm{CMs})$, and cardiac progenitor cells (CPCs) [16-18]. Bone marrow stem cells promote angiogenesis and modulate inflammation in a paracrine fashion, but cannot directly achieve the regeneration of functional myocardium [19-21]. Many studies have shown that CMs are the ideal cell type for production of cardiac tissue, but it is very difficult to isolate human CMs for clinical application. Therefore, CMs derived from pluripotent stem cells could be the most feasible cell source for generation of cardiac tissue in combination with biomaterials, but purified CMs cannot form vascularized tissue or grafts when seeded into biomaterials.

In contrast, embryonic CPCs can be differentiated from embryonic stem/induced pluripotent cells and then manipulated to undergo differentiation into various types of cardiac cells, including CMs, vascular endothelial cells, and smooth muscle cells. Therefore, CPCs could be the ideal cell source for engineering of vascularized tissues or grafts [22, 23]. Embryonic CPCs can be identified by a specific marker (Isl1) and have been isolated from the second heart field [24, 25]. As bona-fide cardiac progenitors, $\mathrm{Isl1}^{+} \mathrm{CPCs}$ may be a more suitable cell source for cardiac tissue engineering and heart regeneration [26-32].

Decellularized porcine small intestinal submucosa extracellular matrix (SIS-ECM) is a xenogeneic biodegradable scaffold with properties that allows its use as a biomaterial [33, 34]. Several studies have demonstrated that SIS-ECM promotes tissue repair in regenerative applications such as wound healing [33, 35, 36]. SISECM can serve as a scaffold that provides adequate three-dimensional support for transplanted cells, potentially sustaining cell survival and promoting proliferation [33, 37]. In addition, it does not trigger an antigenic response and can induce regeneration of native tissue after transplantation in vivo [38]. Therefore, in this study we aim to determine the therapeutic potential of $\mathrm{Isl}^{+} \mathrm{CPCs}$ seeded in SIS-ECM to repair MI heart.

\section{Methods}

\section{Culture, differentiation, and characterization of cells}

Mouse embryonic stem cells (ES) were cultured according to the protocol reported previously and differentiation into CPCs was performed according to a previously published protocol with some modifications [39]. In brief, mES cells were digested with TrypLE (Invitrogen) and suspended in differentiation medium 1 (DM1: IMDM supplemented with Ham's F12, bovine serum albumin, B27, N2 (Invitrogen), monothioglycerol, and vitamin C (Sigma-Aldrich)) at a density of 75,000 cells $/ \mathrm{ml}$ for culture in a Petri dish for 48 hours. The embryoid bodies (EBs) that formed were then harvested, dissociated, and cultured in DM1 supplemented with $5 \mathrm{ng} / \mathrm{ml}$
VEGF, $5 \mathrm{ng} / \mathrm{ml}$ Activin A, and $0.8 \mathrm{ng} / \mathrm{ml}$ BMP4 (R\&D Systems, Minneapolis, MN, USA) at a density of 100,000 cells $/ \mathrm{ml}$ in a Petri dish for 40 hours. The EBs were collected again, dissociated, and cultured in $0.1 \%$ gelatin-coated cell culture dishes in differentiation medium 2 (DM2: StemPro-34 SFM supplemented with vitamin C, glutamine (Invitrogen), monothioglycerol (Sigma-Aldrich), $5 \mathrm{ng} / \mathrm{ml}$ VEGF, $10 \mathrm{ng} / \mathrm{ml} \mathrm{bFGF}$, and 25 $\mathrm{ng} / \mathrm{ml}$ FGF10 (R\&D Systems)) for 32 hours to generate Isl1 ${ }^{+}$CPCs. The Isl1 $1^{+}$CPCs were collected and seeded in SIS-ECM or culture plate, and then cultured in DM2 medium without growth factors (no VEGF, bFGF, or FGF10) for 7-day differentiation. The cells were characterized by immunofluorescence staining using the standard protocol. Fluorescence images were obtained with an Olympus BX53 fluorescence microscope (Olympus Corporation, Tokyo, Japan).

\section{Assessment of the biocompatibility of SIS-ECM with $|s| 1^{+}$CPCs}

Porcine SIS-ECM was kindly donated by CorMatrix Cardiovascular, Inc. (Atlanta, GA, USA). Isl1 ${ }^{+} \mathrm{CPCs}$ were prestained with Dil (Invitrogen) and were seeded directly into 24-well plates or into SIS-ECM before culture in DM2. The cell density in SIS-ECM was $1.0 \times 10^{5} / \mathrm{mm}^{3}$. Fluorescence images were captured at 24 hours after seeding, and then cck8 reagent (Dojindo Molecular Technologies, Rockville, MD, USA) was added to the wells and culture was continued for another 2 hours. An aliquot $(200 \mu \mathrm{l})$ of culture medium was transferred to a 96-well plate and the absorbance was measured at $450 \mathrm{~nm}$ using a microplate reader. After 24 hours of culture, some of the SIS-ECM/cell constructs were fixed overnight at $4{ }^{\circ} \mathrm{C}$ with $2.5 \%$ phosphate-buffered glutaraldehyde (Sigma-Aldrich), and post-fixed for 1 hour with $1 \%$ osmium tetroxide (Sigma-Aldrich). The samples were then rinsed three times with PBS, dehydrated through a graded ethanol series, and dried using hexamethyldisilazane (SigmaAldrich). Processed SIS-ECM/cell constructs were cut open at the center, sputter-coated with gold, and imaged at $10 \mathrm{kV}$ using a Philips XL30 FEG scanning electron microscope (Philips, the Netherlands) to detect cell adhesion. On days 1 and 7 of culture, SIS-ECM/ cell constructs were fixed with $4 \%$ paraformaldehyde for $10 \mathrm{~min}$, and then were placed in 5\% sucrose-PBS for 1 hour and in 15\% sucrose-PBS for another 1 hour. Specimens were embedded in CRYO-OCT Compound (Andwin Scientific, Tryon, NC, USA), frozen at $-20{ }^{\circ} \mathrm{C}$, and cut into $10-\mu \mathrm{m}$ sections. Cells in the SIS-ECM/cell constructs were stained by DAPI $(1: 10,000)$ at 24 hours after seeding. On day 7 , the differentiated cells in culture plates and frozen sections of SIS-ECM/cell constructs were fixed with $4 \%$ paraformaldehyde for immunofluorescence staining by the standard protocol. 


\section{Animal models}

This study was approved by the Committee for Animal Research of the University of Michigan and was performed in accordance with the recommendations of the American Association for the Accreditation of Laboratory Animal Care.

\section{Induction of $\mathrm{MI}$ and transplantation of SIS-ECM patches seeded with IsI $1^{+}$CPCs}

MI was induced in nude (NU-Foxn1nu) mice (Charles River Laboratories, Wilmington, MA, USA) by permanent ligation of the left anterior descending coronary artery (LAD). Then $3.6 \mathrm{~mm}^{3}$ of SIS-ECM (depth $3 \mathrm{~mm}$, width 3 $\mathrm{mm}$, height $0.4 \mathrm{~mm}$ ) was seeded with $3.6 \times 10^{5} \mathrm{Isl}^{+} \mathrm{CPCs}$ and incubated in DM2 medium without growth factors for 7 days before transplantation. Fibrin gel (EVICEL ${ }^{\oplus}$ Fibrin Sealant (Human); Ethicon, Somerville, MA, USA) was applied to the edges of SIS-ECM patches containing Isl1 ${ }^{+}$CPC-differentiated cardiac cells with DM2 medium for attachment of the patches to the infarcted region of the left ventricle after induction of MI or to the left ventricle of normal hearts.

\section{Histological analyses}

Histological studies were performed by standard protocols. Briefly, mice were sacrificed and their hearts were perfused with $20 \% \mathrm{KCl}$, fixed with zinc fixative solution (BD Pharmingen), and dehydrated with 30\% sucrose. After embedding in paraffin, the samples were sectioned and processed for Masson's trichrome staining. Images were captured with an Aperio (Leica Biosystems, Buffalo Grove, IL, USA) and infarct size was measured using Image J software.

\section{Real-time polymerase chain reaction analysis}

Total RNA was extracted from cells in culture plates, cells in SIS-ECM, or the left ventricles of mice using an RNAeasy Mini kit (Qiagen, Valencia, CA, USA), and 1 $\mu \mathrm{g}$ of total RNA was converted to cDNA with reverse transcriptase in a $10-\mu \mathrm{l}$ reaction mixture. We tested the products of each RT reaction by regular PCR to confirm reverse transcription. Real-time PCR was carried out with a SYBR Green PCR Master Mix kit (Invitrogen, Carlsbad, CA, USA) and the 7300 Sequence Detection system (ABI).

\section{Echocardiography}

Echocardiography was performed at 28 days after MI using a Vevo 770 system (Visualsonic, Toronto, Canada). Using M-mode tracings, the following parameters were measured by an investigator blinded to the treatment of the mice: the LV ejection fraction (EF), cardiac output, end-diastolic volume, and LV end-diastolic and endsystolic dimensions (LVEDD and LVESD, respectively).
In addition, LV fractional shortening (LVFS) was calculated according to the following equation:

$$
\text { LVFS }=[(\text { LVEDD }- \text { LVESD }) / \text { LVEDD }] \times 100 .
$$

\section{Statistical analysis}

Results are presented as the mean \pm SD. Data were analyzed by one-way analysis of variance followed by Fisher's least significant difference test. Differences were considered significant at $p<0.05$.

\section{Results}

IsI $1^{+}$CPCs were easily attached to and proliferated normally in SIS-ECM

Isl1 ${ }^{+}$CPCs were obtained as described previously. Differentiation of mES cells was induced by a published EB-based cardiac differentiation protocol with minor modifications. Isl1 ${ }^{+} \mathrm{CPCs}$ were identified by immunofluorescence staining (Fig. 1a, b). Proliferation $\mathrm{Isl1}^{+}$CPCs (Additional file 1: Figure S1) were harvested and seeded into the SIS-ECM patches (Fig. 1c, d) at $1.0 \times 10^{5}$ cells $/ \mathrm{mm}^{3}$. In order to investigate whether the patches supported cell survival, viable Isl1 ${ }^{+}$CPCs prestained with Dil (Invitrogen) were observed by bright-field and fluorescence microscopy (Fig. 1e, f) at 24 hours after seeding. DAPI staining of frozen sections also showed that Isl $^{+}$CPCs remained viable in SIS-ECM patches (Fig. 1g, h). To investigate attachment of Isl1 ${ }^{+}$CPCs to the SIS-ECM patch material, patches were seeded with Isl1 ${ }^{+}$CPCs and scanning electron microscopy was performed, revealing that CPCs spread over and became attached to the patches (Fig. 1i). In addition, the proliferation rate of CPCs in SIS-ECM and in culture plates (control) was compared by the Cell Counting Kit-8 (CCK-8) assay, revealing no significant difference of proliferation between SIS-ECM and control culture (Fig. 1j). In contrast, as a control, we found that it was more challenging to seed ESC-derived CMs into SISECM patches, which could be partially due to the relatively larger size and irregularity of the cell shape of the CMs.

IsI $1^{+}$CPCs differentiated into CMs and endothelial cells in SIS-ECM

To evaluate the multilineage differentiation potential of $\mathrm{Isl1}^{+} \mathrm{CPCs}$, we investigated the transition of cells seeded into the SIS-ECM from CPCs to CMs and endothelial cells. Immunofluorescence revealed differentiation of $\mathrm{Isl}^{+} \mathrm{CPCs}$ into CMs ( $\alpha$-actinin-positive and cTnT-positive cells; Fig. 2b, d) and endothelial cells (CD31-positive cells; Fig. 2e) at 7 days after seeding into SIS-ECM or culture plates (Fig. 2a, c, e). Real-time PCR showed that there were no significant differences 

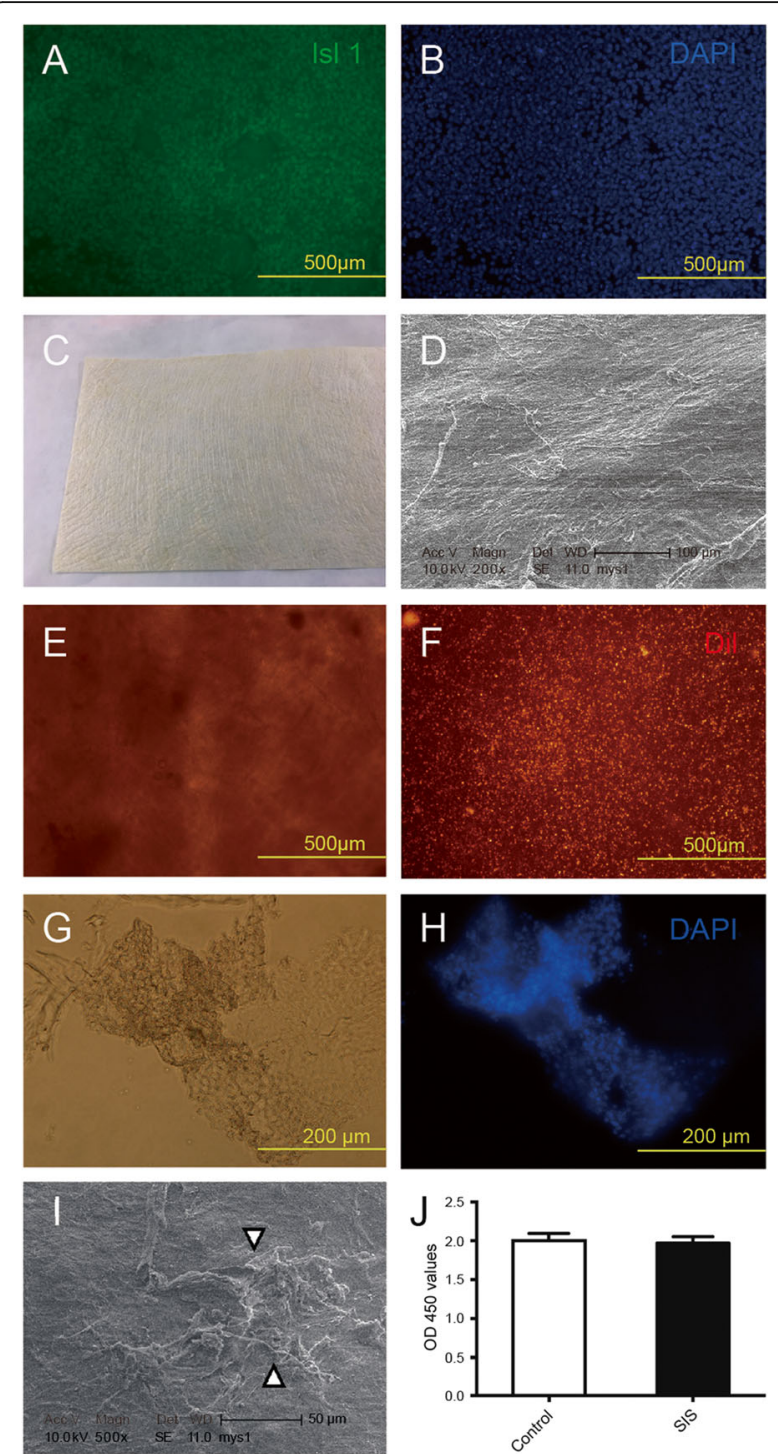

Fig. $1 \mathrm{sl} \mid 1^{+} \mathrm{CPCs}$ remain viable and attach to the extracellular matrix of the patch material (SIS-ECM). a, b $|s| 1^{+}$CPCS. c Extracellular matrix (SIS-ECM) patch material. d Scanning electron micrograph of SIS-ECM. e, $\mathbf{f}$ Viable $|\mathrm{s}| 1^{+}$CPCs prestained by Dil in SIS-ECM obtained by bright-field (e) and fluorescence (f) microscopy. g, h Images of frozen sections of $\mathrm{IsI}^{+}{ }^{+}$CPCS seeded into SIS-ECM obtained by bright-field (g) and fluorescence microscopy (h). i Scanning electron microscopy shows attachment of $|\mathrm{s}| 1^{+}$CPCs (arrowhead) in SISECM. j CPC proliferation rate in SIS-ECM compared to standard culture (control) measured using the Cell Counting Kit-8 (CCK-8) assay. SIS small intestinal submucosa

of $\alpha$-actinin, cTnT, and CD31 mRNA expression in cells between SIS-ECM and control culture.

IsI $1{ }^{+}$CPCs seeded in SIS-ECM formed a multilayered cardiac tissue-like structure and responded to $\beta$-adrenergic

stimulation

HE-stained cross-sections of SIS-ECM showed a multilayered structure (Fig. 3a), and indicated that a multilayered
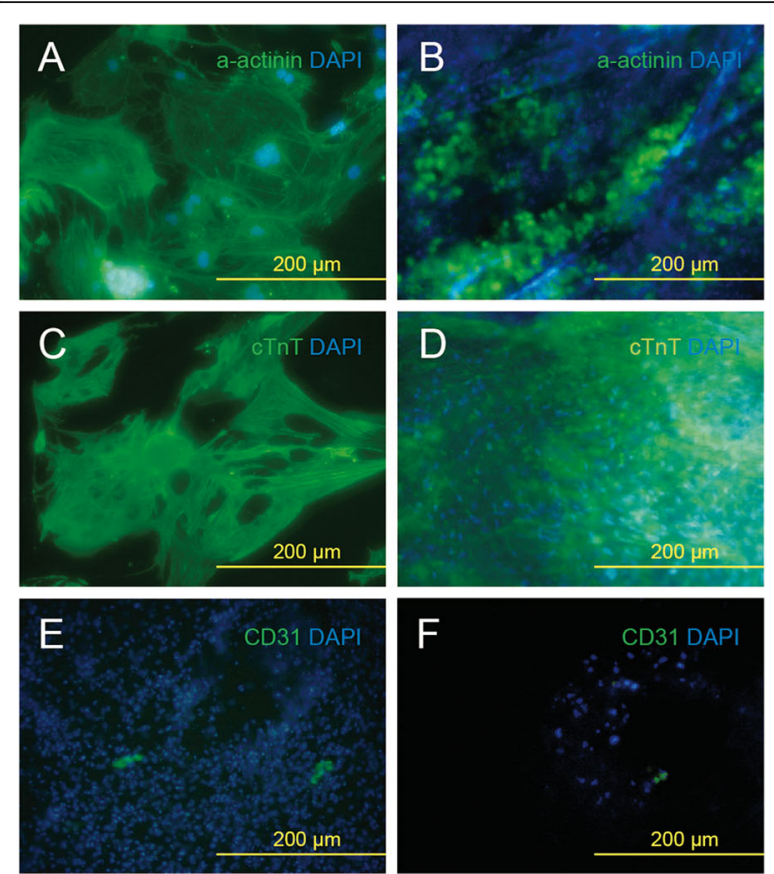

G

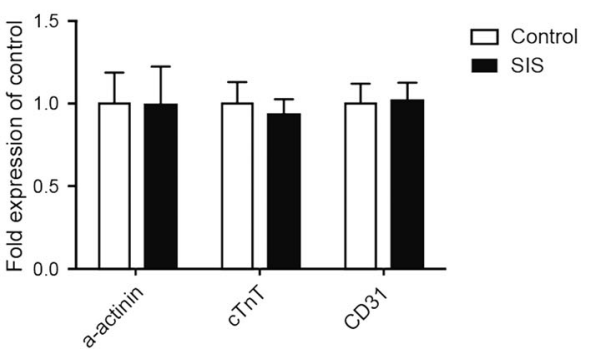

Fig. $2|s| 1^{+}$CPCs differentiate into CMs and endothelial cells after seeding into SIS-ECM. a, c IsI $1^{+}$CPC-derived CMs (a-actinin-positive and CTnT-positive) in culture obtained by fluorescence microscopy. b, $\mathbf{d}|\mathrm{s}| 1^{+}$CPC-derived CMs (a-actinin-positive and CTnT-positive) in SIS-ECM obtained by fluorescence microscopy. e Is| $1^{+} \mathrm{CPC}$-derived endothelial cells $\left(\mathrm{CD} 31^{+}\right)$in culture obtained by fluorescence microscopy. f $|\mathrm{s}| 1^{+}$CPC-derived endothelial cells $\left(\mathrm{CD} 31^{+}\right)$in SIS-ECM obtained by fluorescence microscopy. $\mathbf{g}$ Relative quantitative RNA expression of a-actinin, CTnT, and CD31 by CPC-derived CMs or endothelial cells growing in SIS-ECM compared to standard culture plates. SIS small intestinal submucosa

cardiac tissue-like cell sheet (Fig. 3b) was generated by seeding Isl1 ${ }^{+}$CPCs into SIS-ECM. To investigate the response of the cardiac tissue-like cell sheet to $\beta$-adrenergic stimulation, $10 \mu \mathrm{M}$ isoproterenol was added to the culture medium, resulting in a reversible significant increase in the frequency of contraction (Fig. 3c).

\section{Transplantation of SIS-ECM patches seeded with CPCS reduced myocardial scarring after $\mathrm{MI}$}

The formation of beating multilayered tissue-like structures in SIS-ECM after seeding with CPCs prompted us to examine the patch's function in heart repair in vivo. SIS-ECM was seeded with $\mathrm{Isl} 1^{+}$CPCs and cultured in 

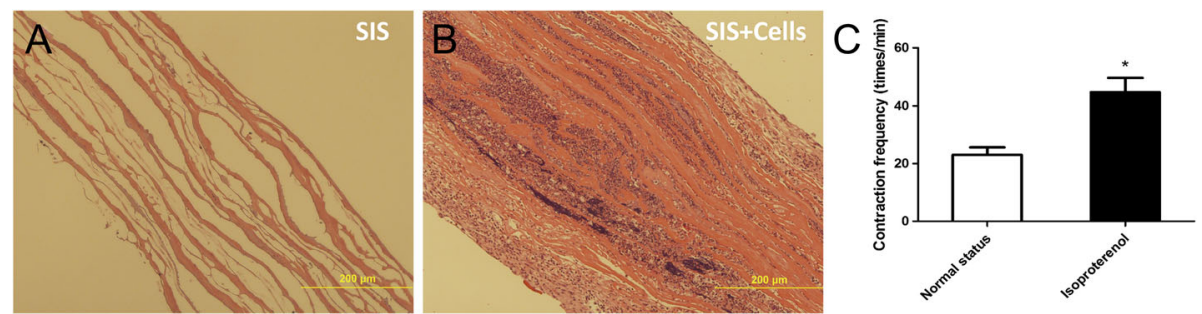

Fig. 3 Structure of SIS-ECM seeded with CPCS for 1 week and response to $\beta$-adrenergic stimulation. $\mathbf{a}$, b Cross-sectional images (HE staining) of SIS-ECM (a) and SIS-ECM seeded with CPCS after 1 week (b). c Contraction rate of SIS-ECM seeded with CPCs before and after the addition of $10 \mu \mathrm{M}$ isoproterenol on day 8 of culture. Data expressed as mean \pm SD. $n=5$. ${ }^{*} p<0.05$ vs basal state. SIS small intestinal submucosa

vitro for 7 days before transplantation. Nude mice (Charles River Laboratories, Wilmington, MA, USA) were used to generate MI by permanent ligation of the left anterior descending coronary artery (LAD); immediately after MI, SIS-ECM and SIS-ECM-CPC patches were transplanted to the surface area of infarcted region of the left ventricle. Gel was applied to the edges of SISECM patches to improve attachment of the patches to the hearts. Mice were euthanized on day 28 after transplantation and the hearts were harvested for histological analysis. As shown in Fig. 4, transplantation of SIS-ECM or SIS-ECM-CPC to healthy mice did not affect the heart morphology (Fig. 4, b, compare $\mathrm{c}$ to $\mathrm{d}$ and e). Transplantation of SIS-ECM to MI heart appeared to have modest effect on reducing the scar area (Fig. 4, b, compare $g$ to f; $p=0.061$ ). In contrast, SIS-ECM with CPC seeding significantly reduced the scar area compared with the MI group (Fig. 4, b, compare h to f; $p=$ 0.003). This indicated that transplantation of SIS-ECM patches seeded with CPCs maximally reduced infarct size after MI.

\section{Transplantation of SIS-ECM patches with CPCs improved cardiac function after MI}

Echocardiographic examination was performed 28 days after transplantation of SIS-ECM-CPCs. There were no significant differences among the Sham + Patch, Sham + Patch + Cell, and Sham groups (Fig. 5, a, c, g, h), suggesting that cell-seeded patch implantation did not affect the function of normal hearts. In mice with MI, echocardiography showed a significant decrease of LVEF $(33.48 \pm 6.36 \%)$ and LVFS $(18.88 \pm 3.81 \%)$ and a significant increase of LVEDD $(4.74 \pm 0.34 \%)$ and LVESD $(3.99 \pm 0.38 \%)$ compared with Sham mice (Fig. 5, a, d, g-j). Transplantation of the patch alone increased the LVEF modestly in MI mice (Fig. 5, d, e, g). In contrast, transplantation of Patch + Cell significantly increased the $\operatorname{LVEF}(62.16 \pm 8.96 \%)$ and LVFS $(32.44 \pm 6.54 \%)$ and decreased the LVEDD $(3.41 \pm 0.35 \%)$ and LVESD $(2.32 \% \pm$ $0.38 \%$ ) compared with the MI only mice (Fig. $5, \mathrm{~d}, \mathrm{f}, \mathrm{g}-\mathrm{j}$ ). These findings suggested that implantation of SIS-ECM

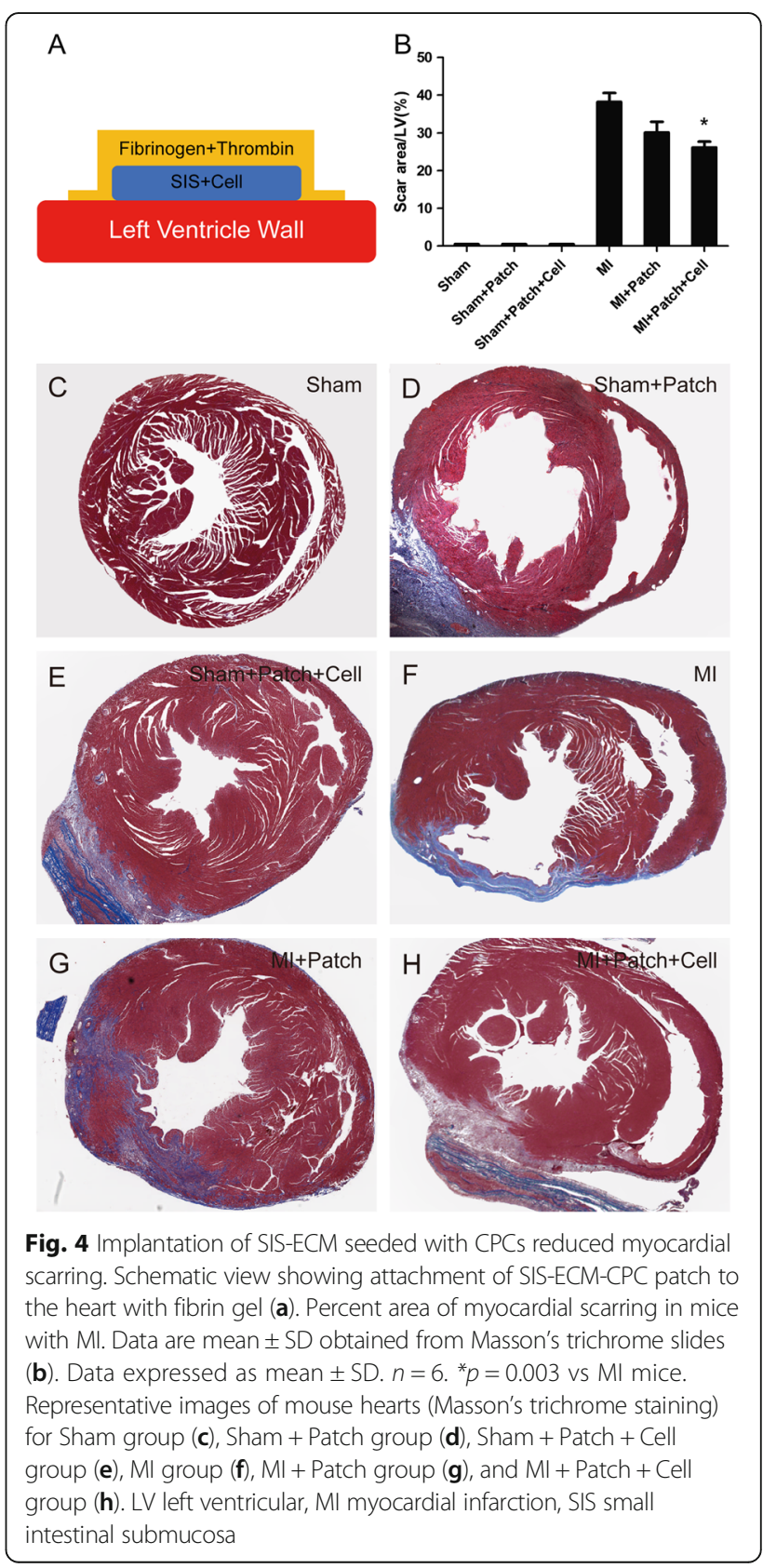




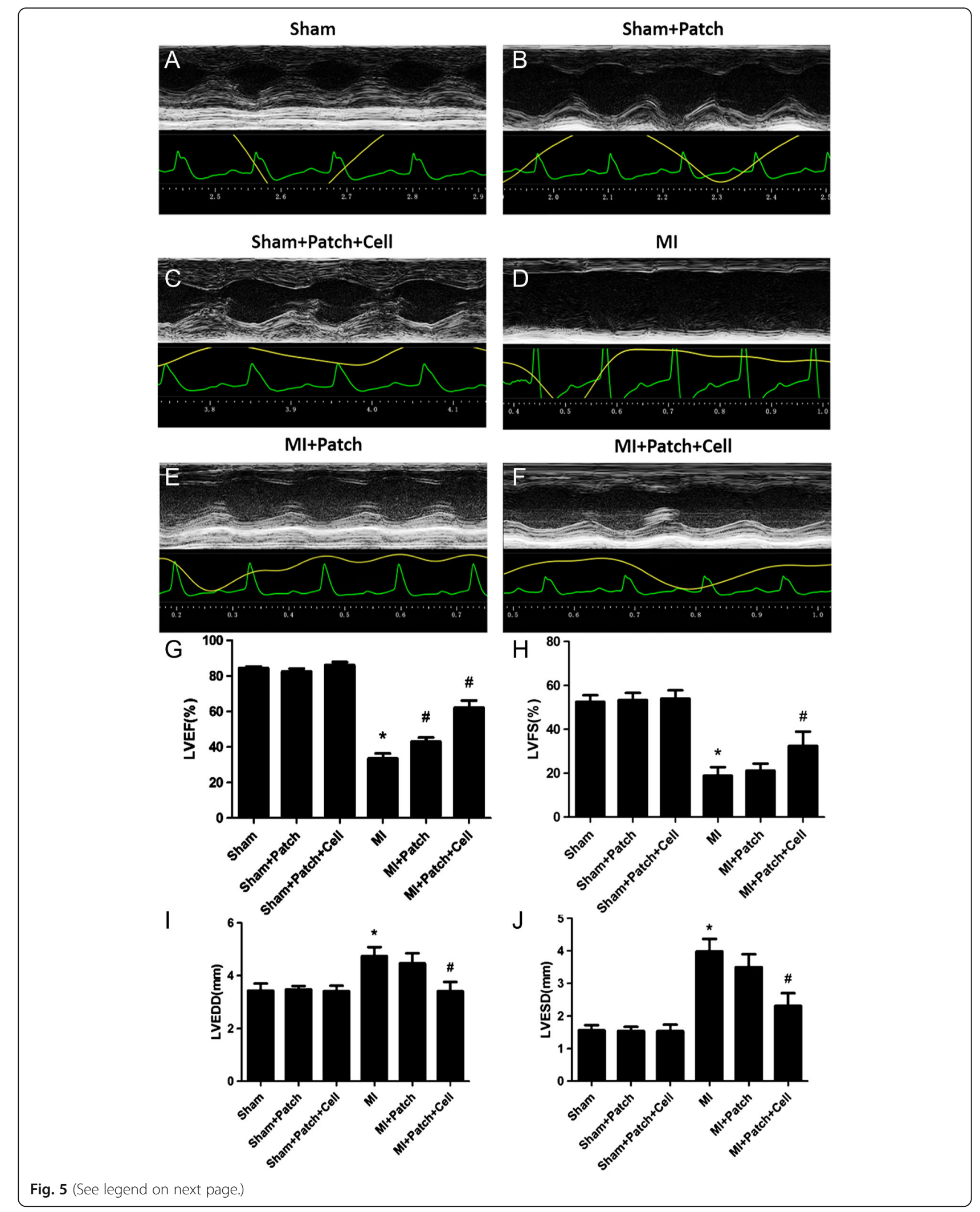


(See figure on previous page.)

Fig. 5 Implantation of SIS-ECM-CPC improved cardiac function in mice with MI. Representative M-mode echocardiographic images obtained in Sham (a), Sham + Patch (b), Sham + Patch + Cell (c), Ml control (d), Ml + Patch (e), and Ml + Patch + Cell (f) groups. Quantitative cardiac function analysis of LVEF (g), LVFS (h), LVEDD (i), and LVESD (j) 4 weeks after permanent LAD occlusion of the six groups. Data expressed as mean \pm SD. $n=6 . \mathrm{Ml}+$ Patch + Cell vs sham mice, ${ }^{*} p<0.001 ; \mathrm{Ml}+$ Patch + Cell vs Ml mice, $\# p<0.004$. Modest or no statistical significance was detected between $\mathrm{MI}+$ Patch and $\mathrm{Ml}$ groups. $n=6 . \mathrm{MI}+$ Patch vs MI mice, LVEF, $\# p=0.034$. LVEF left ventricular ejection fraction, LVFS left ventricular fractional shortening, Ml myocardial infarction

seeded with CPC-derived CMs could be an effective strategy to ameliorate LV dysfunction with heart failure after MI.

Transplantation of SIS-ECM-CPC patches reduced BNP, ANP, Collagen I, Collagen III, and TGF- $\beta$ mRNA expression in the LV myocardium after MI

Real-time quantitative PCR analysis indicated that expression of BNP, ANP, Collagen I, Collagen III, and TGF- $\beta$ mRNA was increased in the LV myocardium of mice with MI-induced heart failure compared with sham mice mice (Fig. 6a-e). Consistent with our echocardiography findings, implantation of SIS-ECM seeded with CPC-derived CMs reduced BNP, ANP, Collagen I, Collagen III, and TGF- $\beta$ mRNA expression in the LV myocardium (Fig. 6a-e). These data demonstrate that the transplantation of SIS-ECM-CPC significantly prevented heart failure, improved cardiac function, and reduced myocardial fibrosis in mice after MI.

\section{Discussion}

In this study, we investigated whether transplantation of SIS-ECM seeded with Isl $1^{+}$CPCs could improve cardiac function and alleviate myocardial damage after MI. To generate a high yield of Isl $1^{+} \mathrm{CPCs}$ from $\mathrm{mES}$ cells, we employed modified EB-based differentiation based on previous protocols [39]. In order to determine whether Isl1 ${ }^{+}$CPCs could survive in SIS-ECM and attach to the biomaterial, we first investigated the viability and attachment of $\mathrm{Isl1}^{+} \mathrm{CPCs} 24$ hours after seeding into SIS-ECM. The findings suggested that SIS-ECM provide a suitable environment for growth and act as a

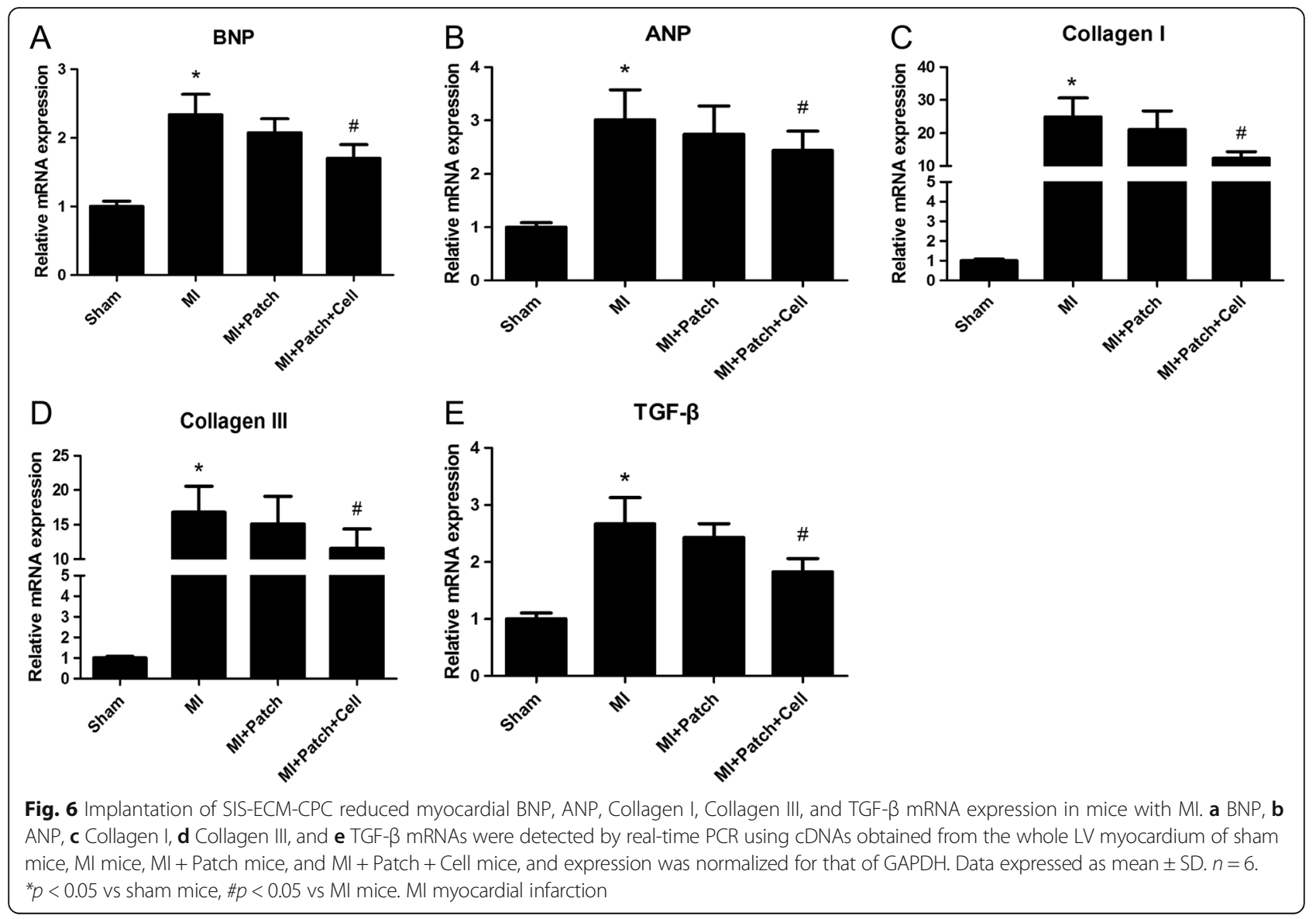


scaffold for Isl1 $1^{+}$CPCs. We compared differentiation of Isl1 $1^{+}$CPCs into CMs and endothelial cells in SIS-ECM with differentiation under normal culture conditions. Our data indicated no significant differences in the differentiation of CMs and endothelial cells between SIS-ECM and standard culture. This suggested that $\mathrm{Isl}^{+} \mathrm{CPCs}$ could effectively differentiate into CMs and endothelial cells after seeding into SIS-ECM, allowing utilization for engineering of vascularized cardiac tissue and cardiac tissue regeneration (Figs. 1, 2, and 3).

In the present study, CPCs were seeded into porcine SIS-ECM, and 7 days after seeding we could observe the alignment of $\mathrm{CPC}$-derived $\mathrm{CMs}$ along the longitudinal axis of the SIS fibers. In addition, we observed the spontaneous contraction of SIS-ECM seeded with $\mathrm{CPC}$-derived $\mathrm{CMs}$. The contraction rate of the SIS-ECM/CPC-derived CM constructs was significantly increased by short-term $\beta$-adrenergic stimulation with isoproterenol. These findings suggested the formation of a functional patch with contractile activity of CMs.

We believe that our studies represent significant progress compared to a previous study in which a myocardial patch was generated [40]. In the previous study, neonatal rat CMs were seeded to decellularized porcine SIS to form CM sheets adjacent to the SIS layers [40]. The SIS-ECM-CM patch can beat in a somewhat nonsynchronous contraction pattern and preserve heart function after transplantation. However, it is very difficult to isolate human CMs for clinical applications and the seeding of CMs appears very challenging. In particular, it is very inefficient for $\mathrm{CM}$ cells to be seeded inside the SIS-ECM. In contrast, embryonic Isl $1^{+}$CPCs are much easier to be seeded into SISECM. In our studies, we generated a functional spontaneous contracting patch by seeding $\mathrm{Isl}^{+} \mathrm{CPCs}$ into porcine SIS-ECM. Our studies suggest an attractive alternative cell source (human ISL1 ${ }^{+} \mathrm{CPCs}$ ) in future clinical studies.

The major finding of the present study was that transplantation of SIS-ECM-CPCs showed considerable therapeutic potential. To avoid secondary damage, SIS-ECM-CPC patches were attached to the outer surface of the infarcted region of the heart using fibrin gel instead of sutures (Fig. 4a). The cells at the surface of the SIS-ECM-CPC patches were in direct contact with the outer surface of the infarcted myocardium after implantation. Four weeks post implantation, the patches were found to be tightly attached to the surface of the host myocardium and remained viable (Fig. 4 and Additional file 2: Figure S2). Moreover, transplantation of SIS-ECM-CPCs decreased the area of myocardial scarring in mice with MI. The results of real-time PCR showed that implantation of SIS-ECM seeded with $\mathrm{CPC}$-derived $\mathrm{CMs}$ decreased the expression levels of fibrosis related genes such as TGF- $\beta$, Collagen I, and Collagen III. At 4 weeks after permanent ligation, the occurrence of heart failure was confirmed by echocardiography. Transplantation of SISECM-CPCs improved LVEF and LVFS and decreased LVEDD and LVESD at 4 weeks post implantation. In addition, we demonstrated that the transplantation of SIS-ECM-CPC patches did not affect the function of normal hearts (Fig. 5). These data suggested that the patch transplantation method used in this study was safe.

To further determine the therapeutic effect of SISECM-CPC transplantation, we examined the expression of heart failure markers associated with LV systolic dysfunction (Fig. 6). The results of real-time PCR showed that LV myocardial expression of BNP and ANP mRNA was significantly elevated in mice with MI compared with sham mice at 4 weeks after permanent ligation of the LAD. In addition, LV myocardial expression of BNP mRNA was significantly lower in mice from the $\mathrm{MI}+$ Patch group than in untreated mice with MI. These data suggested that the transplantation of SISECM-CPCs was able to inhibit heart failure and improve cardiac function induced by MI. However, the effect of transplantation of SIS-ECM-CPC patches on arrhythmia after MI was not investigated in this study, and will need to be assessed in large animals in the future.

The therapeutic effect of the SIS-ECM-CPC patch is likely due to a combination of several mechanisms. A patch can provide regional mechanical support after transplantation [41, 42]. In addition, spontaneous beating of the patch could be an advantage, which could increase contractility like a small LV assist device [43]. In contrast, patches lacking spontaneous contraction could be a burden to the host heart. Furthermore, stem cell transplantation can attenuate inflammatory response, inhibit fibrosis and stimulate cell proliferation through a paracrine effect [44-47]. The observed decrease of gene expression involved in fibrosis and heart failure (Fig. 6) is consistent with this notion. Future studies will reveal the details of these possible mechanisms, including how the beating rate and rhythm of SIS-ECM-CPC can be coordinated with the host beating rhythm initiated by the sinoatrial node.

\section{Conclusion}

Our studies demonstrated that transplantation of small intestinal submucosa seeded with $\mathrm{Isl}^{+}{ }^{+}$cardiac progenitor cells significantly alleviated myocardial damage and improved cardiac function following myocardial infarction in mice. 


\section{Additional files}

Additional file 1: Figure S1. Showing the proliferation rate of $|s| 1^{+}$cells by staining with mitotic marker ki67. (TIF 862 kb)

Additional file 2: Figure S2. Showing detection of $|\mathrm{s}| 1^{+} \mathrm{CPC}$-derived cell viability in SIS-ECM patches 28 days after transplantation. Frozen sections of mouse hearts subjected to myocardial infarction and transplantation of SIS-ECM-CPC patches before $(\mathbf{A}-\mathbf{C})$ and after fixation by $4 \%$ paraformaldehyde (D) obtained by bright-field $(\mathbf{A})$ and fluorescence microscopy (B-D). (TIF 6084 kb)

\section{Abbreviations}

CM: Cardiomyocyte; CPC: Cardiac progenitor cell; EB: Embryoid body; ESC: Embryonic stem cell; MI: Myocardial infarction; SIS-ECM: Small intestinal submucosa extracellular matrix

\section{Acknowledgments}

The authors thank CorMatrix Cardiovascular, Inc. for kindly providing the SIS-ECM material.

\section{Funding}

This work was supported by the NIH Grant 1R01HL109054, an Inaugural Grant from the Frankel Cardiovascular Center, University of Michigan, and a Pilot Grant from the University of Michigan Health System-Peking University Health Sciences Center Joint Institute for Clinical and Translational Research to ZW. This work was also supported by the National Natural Science Foundation of China (81373570 \& 81173438) to LW.

\section{Availability of data and materials}

The supporting data and materials presented in this publication are available upon request.

\section{Authors' contributions}

LJW was responsible for the in-vitro and in-vivo experiments as well as data interpretation and manuscript writing. EMM was responsible for the in-vitro experiment and support. ST was responsible for generation of the animal model and performed the histological data analysis. IL and LL carried out the cell cultures. SXX and MTL were responsible for conception and design of the experiments. ZW was responsible for the conception and design of the study, edited the manuscript, and provided the funding. All authors read and approved the manuscript for publication.

\section{Ethics approval}

This study was approved by the Committee for Animal Research of the University of Michigan and was performed in accordance with the recommendations of the American Association for the Accreditation of Laboratory Animal Care.

\section{Consent for publication}

All authors provide consent for publication of this manuscript.

\section{Competing interests}

The authors declare that they have no competing interests.

\section{Publisher's Note}

Springer Nature remains neutral with regard to jurisdictional claims in published maps and institutional affiliations.

\footnotetext{
Author details

${ }^{1}$ The First Affiliated Hospital, Guangzhou University of Chinese Medicine, Guangzhou 510405, China. ${ }^{2}$ Department of Cardiac Surgery, Cardiovascular Center, The University of Michigan, Ann Arbor, MI 48109, USA. ${ }^{3}$ Department of Biomedical Engineering, Wayne State University, Detroit, MI 48201, USA. ${ }^{4}$ Faculty of Health Sciences, University of Macau, Macau SAR, China. ${ }^{5}$ Cardiovascular Research Institute, Wayne State University, Detroit, MI 48201 , USA.
}

Received: 1 May 2017 Revised: 2 August 2017

Accepted: 14 September 2017 Published online: 16 October 2017

\section{References}

1. Benjamin EJ, Blaha MJ, Chiuve SE, Cushman M, Das SR, Deo R, de Ferranti SD, Floyd J, Fornage M, Gillespie C, Isasi CR, Jimenez MC, Jordan LC, Judd SE, Lackland D, Lichtman JH, Lisabeth L, Liu S, Longenecker CT, Mackey RH, Matsushita K, Mozaffarian D, Mussolino ME, Nasir K, Neumar RW, Palaniappan L, Pandey DK, Thiagarajan RR, Reeves MJ, Ritchey M, Rodriguez CJ, Roth GA, Rosamond WD, Sasson C, Towfighi A, Tsao CW, Turner MB, Virani SS, Voeks JH, Willey JZ, Wilkins JT, Wu JH, Alger HM, Wong SS, Muntner P, American Heart Association Statistics Committee, Stroke Statistics Subcommittee. Heart Disease and Stroke Statistics-2017 Update: A Report From the American Heart Association. Circulation. 2017;135(10):e146-603.

2. Singh MV, Swaminathan PD, Luczak ED, Kutschke W, Weiss RM, Anderson ME. MyD88 mediated inflammatory signaling leads to CaMKII oxidation, cardiac hypertrophy and death after myocardial infarction. J Mol Cell Cardiol. 2012;52(5):1135-44

3. Orn S, Manhenke C, Ueland T, Damas JK, Mollnes TE, Edvardsen T, Aukrust P Dickstein K. C-reactive protein, infarct size, microvascular obstruction, and left-ventricular remodelling following acute myocardial infarction. Eur Heart J. 2009:30(10):1180-6.

4. Murry $\mathrm{CE}$, Soonpaa $\mathrm{MH}$, Reinecke $\mathrm{H}$, Nakajima $\mathrm{H}$, Nakajima HO, Rubart $\mathrm{M}$, Pasumarthi KB, Virag JI, Bartelmez SH, Poppa V, Bradford G, Dowell JD, Williams DA, Field LJ. Haematopoietic stem cells do not transdifferentiate into cardiac myocytes in myocardial infarcts. Nature. 2004:428(6983):664-8.

5. Quaini F, Urbanek K, Beltrami AP, Finato N, Beltrami CA, Nadal-Ginard B, Kajstura J, Leri A, Anversa P. Chimerism of the transplanted heart. N Engl J Med. 2002;346(1):5-15.

6. Bergmann O, Bhardwaj RD, Bernard S, Zdunek S, Barnabe-Heider F, Walsh S, Zupicich J, Alkass K, Buchholz BA, Druid H, Jovinge S, Frisen J. Evidence for cardiomyocyte renewal in humans. Science. 2009;324(5923):98-102.

7. Soler-Botija C, Bago JR, Bayes-Genis A. A bird's-eye view of cell therapy and tissue engineering for cardiac regeneration. Ann N Y Acad Sci. 2012;1254:57-65.

8. Muller-Ehmsen J, Whittaker P, Kloner RA, Dow JS, Sakoda T, Long TI, Laird PW, Kedes L. Survival and development of neonatal rat cardiomyocytes transplanted into adult myocardium. J Mol Cell Cardiol. 2002;34(2):107-16.

9. van Laake LW, Passier R, Monshouwer-Kloots J, Verkleij AJ, Lips DJ, Freund C, den Ouden K, Ward-van Oostwaard D, Korving J, Tertoolen LG, van Echteld CJ, Doevendans PA, Mummery CL. Human embryonic stem cell-derived cardiomyocytes survive and mature in the mouse heart and transiently improve function after myocardial infarction. Stem Cell Res. 2007;1(1):9-24

10. Hattan N, Kawaguchi H, Ando K, Kuwabara E, Fujita J, Murata M, Suematsu M, Mori H, Fukuda K. Purified cardiomyocytes from bone marrow mesenchymal stem cells produce stable intracardiac grafts in mice. Cardiovasc Res. 2005;65(2):334-44.

11. Hou D, Youssef EA, Brinton TJ, Zhang P, Rogers P, Price ET, Yeung AC, Johnstone $\mathrm{BH}$, Yock PG, March KL. Radiolabeled cell distribution after intramyocardial, intracoronary, and interstitial retrograde coronary venous delivery: implications for current clinical trials. Circulation. 2005; 112 (9 Suppl):1150-6.

12. Hudson W, Collins MC, deFreitas D, Sun YS, Muller-Borer B, Kypson AP. Beating and arrested intramyocardial injections are associated with significant mechanical loss: implications for cardiac cell transplantation. Cardiothoracic. 2007;142(2):263-7.

13. Roche ET, Hastings CL, Lewin SA, Shvartsman DE, Brudno Y, Vasilyev NV, O'Brien FJ, Walsh CJ, Duffy GP, Mooney DJ. Comparison of biomaterial delivery vehicles for improving acute retention of stem cells in the infarcted heart. Biomaterials. 2014;35(25):6850-8.

14. Kuraitis D, Giordano C, Ruel M, Musaro A, Suuronen EJ. Exploiting extracellular matrix-stem cell interactions: a review of natural materials for therapeutic muscle regeneration. Biomaterials. 2012;33(2):428-43.

15. Liu J, Zhang Z, Liu Y, Guo C, Gong Y, Yang S, Ma M, Li Z, Gao WQ, He Z. Generation, characterization, and potential therapeutic applications of cardiomyocytes from various stem cells. Stem Cells Dev. 2012;21(12):2095-110

16. Feyen DA, Gaetani R, Deddens J, van Keulen D, van Opbergen C, Poldervaart M, Alblas J, Chamuleau S, van Laake LW, Doevendans PA, Sluijter JP. Gelatin microspheres as vehicle for cardiac progenitor cells delivery to the myocardium. Adv Healthc Mater. 2016;5(9):1071-9. 
17. Nakajima K, Fujita J, Matsui M, Tohyama S, Tamura N, Kanazawa H, Seki T, Kishino Y, Hirano A, Okada M, Tabei R, Sano M, Goto S, Tabata Y, Fukuda K. Gelatin hydrogel enhances the engraftment of transplanted cardiomyocytes and angiogenesis to ameliorate cardiac function after myocardial infarction. PLoS One. 2015;10(7):e0133308.

18. Chi NH, Yang MC, Chung TW, Chen JY, Chou NK, Wang SS. Cardiac repair achieved by bone marrow mesenchymal stem cells/silk fibroin/hyaluronic acid patches in a rat of myocardial infarction model. Biomaterials. 2012; 33(22):5541-51.

19. Endo J, Sano M, Fujita J, Hayashida K, Yuasa S, Aoyama N, Takehara Y, Kato O, Makino S, Ogawa S, Fukuda K. Bone marrow derived cells are involved in the pathogenesis of cardiac hypertrophy in response to pressure overload. Circulation. 2007:116(10):1176-84.

20. Blondiaux E, Pidial L, Autret G, Rahmi G, Balvay D, Audureau E, Wilhelm C, Guerin $\mathrm{CL}$, Bruneval $\mathrm{P}$, Silvestre JS, Menasche P, Clement O. Bone marrowderived mesenchymal stem cell-loaded fibrin patches act as a reservoir of paracrine factors in chronic myocardial infarction. J Tissue Eng Regen Med. 2017 doi: 10.1002/term.2255.

21. Simari RD, Pepine CJ, Traverse JH, Henry TD, Bolli R, Spoon DB, Yeh E, Hare JM, Schulman IH, Anderson RD, Lambert C, Sayre SL, Taylor DA, Ebert RF, Moye LA. Bone marrow mononuclear cell therapy for acute myocardial infarction: a perspective from the cardiovascular cell therapy research network. Circ Res. 2014;114(10):1564-8.

22. Beltrami AP, Barlucchi L, Torella D, Baker M, Limana F, Chimenti S, Kasahara H, Rota M, Musso E, Urbanek K, Leri A, Kajstura J, Nadal-Ginard B, Anversa P. Adult cardiac stem cells are multipotent and support myocardial regeneration. Cell. 2003;114(6):763-76.

23. Zhang $Y, Y u$ Y, Chen $\mathrm{H}$, Ozbolat IT. Characterization of printable cellular microfluidic channels for tissue engineering. Biofabrication. 2013;5(2):025004.

24. Li X, Yang Y, Bu L, Guo X, Tang C, Song J, Fan N, Zhao B, Ouyang Z, Liu Z, Zhao Y, Yi X, Quan L, Liu S, Yang Z, Ouyang H, Chen YE, Wang Z, Lai L. Rosa26-targeted swine models for stable gene over-expression and Cremediated lineage tracing. Cell Res. 2014;24(4):501-4.

25. Wu SM, Chien KR, Mummery C. Origins and fates of cardiovascular progenitor cells. Cell. 2008;132(4):537-43.

26. Bu L, Jiang X, Martin-Puig S, Caron L, Zhu S, Shao Y, Roberts DJ, Huang PL Domian IJ, Chien KR. Human ISL1 heart progenitors generate diverse multipotent cardiovascular cell lineages. Nature. 2009;460(7251):113-7.

27. Laugwitz KL, Moretti A, Lam J, Gruber P, Chen Y, Woodard S, Lin LZ, Cai CL, Lu MM, Reth M, Platoshyn O, Yuan JX, Evans S, Chien KR. Postnatal isl1+ cardioblasts enter fully differentiated cardiomyocyte lineages. Nature. 2005; 433(7026):647-53.

28. Cai CL, Liang X, Shi Y, Chu PH, Pfaff SL, Chen J, Evans S. Isl1 identifies a cardiac progenitor population that proliferates prior to differentiation and contributes a majority of cells to the heart. Dev Cell. 2003;5(6):877-89.

29. Moretti A, Caron L, Nakano A, Lam JT, Bernshausen A, Chen Y, Qyang Y, Bu L, Sasaki M, Martin-Puig S, Sun Y, Evans SM, Laugwitz KL, Chien KR. Multipotent embryonic isl1+ progenitor cells lead to cardiac, smooth muscle, and endothelial cell diversification. Cell. 2006;127(6):1151-65.

30. Liu Q, Tian S, Zhao C, Chen X, Lei I, Wang Z, Ma PX. Porous nanofibrous poly(L-lactic acid) scaffolds supporting cardiovascular progenitor cells for cardiac tissue engineering. Acta Biomater. 2015;26:105-14.

31. Bartulos O, Zhuang ZW, Huang Y, Mikush N, Suh C, Bregasi A, Wang L, Chang W, Krause DS, Young LH, Pober JS, Qyang Y. ISL1 cardiovascula progenitor cells for cardiac repair after myocardial infarction. JCI Insight. 2016;1(10):e80920.

32. Li Y, Tian S, Lei I, Liu L, Ma P, Wang Z. Transplantation of multipotent Is $\mid 1+$ cardiac progenitor cells preserves infarcted heart function in mice. Am J Transl Res. 2017;9(3):1530-42

33. Lam MT, Nauta A, Meyer NP, Wu JC, Longaker MT. Effective delivery of stem cells using an extracellular matrix patch results in increased cell survival and proliferation and reduced scarring in skin wound healing. Tissue Eng Part A. 2013;19(5-6):738-47

34. Abraham GA, Murray J, Billiar K, Sullivan SJ. Evaluation of the porcine intestinal collagen layer as a biomaterial. J Biomed Mater Res. 2000;51(3):442-52.

35. Chang CW, Petrie T, Clark A, Lin X, Sondergaard CS, Griffiths LG. Mesenchyma stem cell seeding of porcine small intestinal submucosal extracellular matrix for cardiovascular applications. PLoS One. 2016:11(4):e0153412.
36. Lin HK, Godiwalla SY, Palmer B, Frimberger D, Yang Q, Madihally SV, Fung KM, Kropp BP. Understanding roles of porcine small intestinal submucosa in urinary bladder regeneration: identification of variable regenerative characteristics of small intestinal submucosa. Tissue Eng Part B Rev. 2014; 20(1):73-83

37. Kutschka I, Chen IY, Kofidis T, Arai T, von Degenfeld G, Sheikh AY, Hendry SL, Pearl J, Hoyt G, Sista R, Yang PC, Blau HM, Gambhir SS, Robbins RC. Collagen matrices enhance survival of transplanted cardiomyoblasts and contribute to functional improvement of ischemic rat hearts. Circulation. 2006;114(1 Suppl):I167-73.

38. Cayan S, Chermansky C, Schlote N, Sekido N, Nunes L, Dahiya R, Tanagho EA. The bladder acellular matrix graft in a rat chemical cystitis model: functional and histologic evaluation. J Urol. 2002;168(2):798-804.

39. Kattman SJ, Witty AD, Gagliardi M, Dubois NC, Niapour M, Hotta A, Ellis J, Keller G. Stage-specific optimization of activin/nodal and BMP signaling promotes cardiac differentiation of mouse and human pluripotent stem cell lines. Cell Stem Cell. 2011;8(2):228-40.

40. Hata H, Bar A, Dorfman S, Vukadinovic Z, Sawa Y, Haverich A, Hilfiker A. Engineering a novel three-dimensional contractile myocardial patch with cell sheets and decellularised matrix. Eur J Cardiothorac Surg. 2010;38(4):450-5.

41. Kochupura PV, Azeloglu EU, Kelly DJ, Doronin SV, Badylak SF, Krukenkamp IB, Cohen IS, Gaudette GR. Tissue-engineered myocardial patch derived from extracellular matrix provides regional mechanical function. Circulation. 2005;112(9 Suppl):1144-9.

42. Serpooshan V, Zhao M, Metzler SA, Wei K, Shah PB, Wang A, Mahmoudi M, Malkovskiy AV, Rajadas J, Butte MJ, Bernstein D, Ruiz-Lozano P. The effect of bioengineered acellular collagen patch on cardiac remodeling and ventricular function post myocardial infarction. Biomaterials. 2013;34(36):9048-55.

43. Kennedy-Lydon T, Rosenthal N. Cardiac regeneration: All work and no repair? Sci Transl Med. 2017:9(383) doi: 10.1126/scitransImed.aad9019.

44. Kim SW, Houge M, Brown M, Davis ME, Yoon YS. Cultured human bone marrow-derived CD31(+) cells are effective for cardiac and vascular repair through enhanced angiogenic, adhesion, and anti-inflammatory effects. J Am Coll Cardiol. 2014;64(16):1681-94.

45. Ong SG, Huber BC, Lee WH, Kodo K, Ebert AD, Ma Y, Nguyen PK, Diecke S, Chen WY, Wu JC. Microfluidic single-cell analysis of transplanted human induced pluripotent stem cell-derived cardiomyocytes after acute myocardial infarction. Circulation. 2015;132(8):762-71.

46. Uemura $\mathrm{R}, \mathrm{Xu} \mathrm{M}$, Ahmad N, Ashraf M. Bone marrow stem cells prevent left ventricular remodeling of ischemic heart through paracrine signaling. Circ Res. 2006;98(11):1414-21.

47. Levit RD, Landazuri N, Phelps EA, Brown ME, Garcia AJ, Davis ME, Joseph G, Long R, Safley SA, Suever JD, Lyle AN, Weber CJ, Taylor WR. Cellular encapsulation enhances cardiac repair. J Am Heart Assoc. 2013;2(5):e000367.

\section{Submit your next manuscript to BioMed Central and we will help you at every step:}

- We accept pre-submission inquiries

- Our selector tool helps you to find the most relevant journal

- We provide round the clock customer support

- Convenient online submission

- Thorough peer review

- Inclusion in PubMed and all major indexing services

- Maximum visibility for your research

Submit your manuscript at www.biomedcentral.com/submit 